\title{
Bone Marrow Mesenchymal Stem Cells Regulate Coagulation and Inflammation Together in Methotrexate Induced Lung Injury Rat Model
}

\author{
Nawal Zakaria Haggag ${ }^{1 *}$ \\ https://orcid.org/0000-0001-6126-9108
}

Nashwa Ahmed El-Shinnawy ${ }^{1}$

https://orcid.org/0000-0001-6945-3479

Sahar Sobhy Abd-Elhalem ${ }^{1}$

https://orcid.org/0000-0002-0431-6497

\author{
Laila Ahmed Rashed ${ }^{2}$ \\ https://orcid.org/0000-0002-0362-1385
}

\begin{abstract}
${ }^{1}$ Ain Shams University; Faculty of Women for Arts, Science and Education; Zoology Department, Cairo, Egypt; ${ }^{2}$ Cairo University; Faculty of Medicine, Medical Biochemistry Department, Cairo, Egypt.
\end{abstract}

Received: 2018.07.17; Accepted: 2019.06.23.

*Correspondence: Nawal.haggag@women.asu.edu.eg; Tel.: +2-24157804; (N.Z.H.)

\section{HIGHLIGHTS}

- Stem cells suppress lung coagulation and inflammation.

\begin{abstract}
Clinical research has shed the light on the relation between coagulation and inflammation. Coagulation cascade is activated in lung injury resulting in thrombotic and fibrotic lesions. Such a cascade is initiated by inflammation, then the two systems intense each other. New therapies that modulate coagulation and inflammation will be more successful than therapies targeting only one of them. Mesenchymal stem cells showed anti-inflammatory functions in animal models. The role of mesenchymal stem cells in methotrexate induced lung injury model was evaluated, but no studies scoped on the role of stem cells in coagulation associated with inflammation in such models. This study focuses on the therapeutic role of mesenchymal stem cells against the development of clotting in methotrexate induced lung injury rat model. Results showed that mesenchymal stem cells treatment for 4 weeks caused a decrease in lung activated coagulation factors; protease activated receptor-1, fibrinogen, plasminogen activator inhibitor- 1 and platelet count with a decrease in inflammatory factors; tumor necrosis factor- $\alpha$, interferon- $\gamma$, interleukin- 8 , monocyte chemoattractant protein- 1 and total leukocyte count. Thus, mesenchymal stem cells have anti-inflammatory potency against clotting risk in methotrexate induced lung injury model. This opens the outlook for stem cells as a new therapy that moderates coagulation associated with inflammation.
\end{abstract}


Keywords: Coagulation; Inflammation; Lung injury; Mesenchymal Stem Cells; Methotrexate.

\section{INTRODUCTION}

The activation of coagulation cascade is one of the earliest events initiated following tissue injury [1]. A high risk of thrombosis could be caused by coagulation disorders [2,3]. Additionally, coagulation factors play central roles in influencing fibrotic responses [4]. The crosstalk between activated coagulation and inflammation has attracted the attention of clinical research. This coagulation cascade is initiated by inflammatory responses. The effects of inflammation on coagulation are represented in the initiation of coagulants, a decline of anticoagulants and suppression of fibrinolysis. Moreover, when accurate controls of coagulation and inflammation is lost, the mutual amplification contributes to the rapid inception of morbidity and mortality [3]. Consequently, the development of new treatments that goal coagulation and inflammatory mechanisms will be more successful than specific therapies targeting only one of them [3,5]. In acute lung injury, thrombosis represents a major cause of patient mortality and morbidity [5]. In the early stages of lung epithelial injury or inflammation induced by chemicals, the coagulation cascade is activated and thrombotic lesions will be contributed [4]. Following epithelial lung cells injury, leukocytes influx from capillaries into the alveoli and secrete pro-fibrotic mediators encouraging pulmonary fibrosis [6]. Methotrexate (MTX) is a chemotherapeutic agent used in the treatment of malignancies. MTX induces injury in alveolar lung epithelium and thus may considered as a hyper coagulant agent [7]. Bone marrow mesenchymal stem cells (MSCs) arise as an attractive alternative to classic pharmacological treatments. In addition to their ability for differentiation and proliferation, MSCs showed potential anti-inflammatory effects $[8,9]$. Although several studies evaluated the role of MSCs in MTX-induced lung injury models [10,11], no studies scoped on the modulatory effects of MSCs on coagulation as a risk of thrombosis in such models. The objective of this study is to evaluate the potency of mesenchymal stem cells against clotting risk based on their anti-inflammatory functions as a new therapeutic agent that modulates coagulation associated with inflammation together in lung injury rat model induced by MTX.

\section{MATERIAL AND METHODS}

\section{Experimental Animals}

Male albino rats (100-120 g) were acclimatized to the laboratory conditions for one week before the commencement of the experiment. Under conservative conditions, rats were bred and sustained at the experimental animal research unit of Medical Research Centre and Bilharzia, Faculty of Medicine, Ain Shams University. Animals were kept under a 12:12 light/dark cycle with a temperature of $23-25^{\circ} \mathrm{C}$ and allowed unlimited access to chow and water. Animal procedures were achieved in accordance with the Committee for the Purpose of Control and Supervision of Experiments on Animals (CPCSEA) and the National Institutes of Health (NIH) protocol approved by Ain Shams University.

\section{Methotrexate (MTX)}

MTX was purchased from Pfizer Pharmaceuticals Ltd., Australia. Rats were injected intraperitoneally with a single dose of $20 \mathrm{mg} / \mathrm{kg}$ body weight for lung injury induction [12]. 


\section{Preparation of MSCs}

6-week-old male albino rats were used to prepare stem cells; bone marrow was harvested by flushing the tibiae and femurs with Dulbecco's modified Eagle's medium (DMEM, GIBCO/BRL) supplemented with 10\% fetal bovine serum (GIBCO/BRL). The nucleated cells were isolated by a density gradient [Ficoll/Paque (Pharmacia)] and suspended in a complete culture medium containing $1 \%$ penicillin-streptomycin (GIBCO/BRL). Cells were incubated in $5 \%$ humidified $\mathrm{CO}_{2}$ at $37^{\circ} \mathrm{C}$. When cells became $80-90 \%$ confluence, cultures were washed with phosphate buffer saline (PBS, Lonza Company, Swiss) and trypsinized using $0.25 \%$ trypsin $1 \mathrm{mM}$ EDTA (GIBCO/BRL) for $5 \mathrm{~min}$ at $37^{\circ} \mathrm{C}$. Cells were centrifuged and suspended in serumsupplemented medium and incubated in $50 \mathrm{~cm}^{2}$ culture flask (Falcon) [13]. MSCs were identified by their adherence to the plastic as well as by their fibroblast-like morphology. CD90 (+ve), CD29 (+ve) and CD34 (-ve) expressions were detected as markers of MSCs by flow cytometer [14].

\section{Flow Cytometric Analysis of MSCs Surface Markers}

Flow cytometry was implemented on a Fluorescence Activated Cell Sorter flow cytometer (Coulter Epics Elite, Miami, FL, USA). Stem cells were trypsinized and washed with phosphate buffer saline (PBS). A number of $1 \times 10^{5}$ cells were used for each run. The cells were incubated in $100 \mu \mathrm{l}$ of PBS with $3 \mu \mathrm{l}$ for $20 \mathrm{~min}$ at room temperature. Antibody concentration was $0.1 \mathrm{mg} \mathrm{mL}^{-1}$. Cells were washed with PBS and diluted in $200 \mu \mathrm{l}$ of PBS. The expressions of the surface markers were assessed by the mean fluorescence. The percentage of cells positive for CD90, CD29 was determined by subtracting the percentage of cells stained non-specifically with isotype control antibodies. CD34 showed a negative reaction [14]. Flow cytometric assessment was repeated three times and the mean expressions \pm Standard Deviations of CD90 (+ve), CD29 (+ve) and CD34 (-ve) cells of three independent experiments were calculated and graphically presented.

\section{Labeling of MSCs}

MSCs were labeled using $\mathrm{PKH} 26$ fluorescent dye according to Sigma protocol (Saint Louis, Missouri USA). In brief, cells were centrifuged and washed twice in serum-free medium. Cells were pelleted and suspended in dye solution then injected intravenously into rat tail vein [15]. Lung tissues were fixed in $10 \%$ formalin. Unstained lung sections were examined with a fluorescence microscope to detect migrated labeled cells.

\section{Experimental Design}

21 male albino rats were divided into 3 experimental groups (7 rats each): Control group received a single injection of $\mathrm{NaCl}$. (MTX) group received MTX as a single intra-peritoneal injection of $20 \mathrm{mg} / \mathrm{Kg}$ body weight. This group was left for 8 days for lung injury induction. (MTX/MSCs) group injected with MTX as a single intraperitoneal injection of $20 \mathrm{mg} / \mathrm{Kg}$ body weight. This group was also left for 8 days for lung injury induction then injected intravenously with a single dose of $3 \times 10^{6}$ MSCs. After 4 weeks of MSCs transplantation, all rats in all experimental groups were sacrificed under ether anesthesia. Blood samples were withdrawn from all rats by heart acupuncture. Lung tissues were removed, washed with saline and homogenated in phosphate buffer solution at $\mathrm{pH} 7.4$ for the measurement of different experimental parameters. 


\section{Experimental Parameters}

\section{Blood Platelets and Total Leucocyte Count}

Blood samples were withdrawn from all rats by heart acupuncture in dry clean sample tubes containing EDTA for the determination of blood platelets and total leucocyte count [16].

\section{Protease activated receptor-1 (PAR-1)}

PAR-1 was measured using quantitative real time polymerase chain reaction method (QRT-PCR). Briefly, lung tissues of all animals were used for RNA extraction using Qiagen tissue extraction kit (Qiagen, USA). The total RNA was used for cDNA conversion using high capacity cDNA reverse transcription kit (Fermentas, USA) according to manufacturer's instructions [17]. $\beta$-actin gene was used as the reference gene. SYBR Green was used to monitor double stranded DNA synthesis. The primers were as follows: PAR1 sense: 5-CAATAACACGCTGCGGTGG-3; antisense: 5-CTTCTCCGGCACCGATTG-3'. 3 -actin sense: GGTCGGTGTGAACGGATTTGG-3; antisense: 5'ATGTAGGCCATGAGGTCCACC-3" [18]. The amplifications were performed using 40 cycles of denaturation at $95^{\circ} \mathrm{C}$ for 15 seconds and annealing and extension at $60^{\circ} \mathrm{C}$ for 60 seconds. QRT-PCR amplification and analysis were performed using an Applied Biosystem with software version 3.1 (StepOne ${ }^{\mathrm{TM}}$, USA) [17].

\section{Fibrinogen}

Fibrinogen was measured using Fibrinogen Rat ELISA Kit, Catalog Number: ab108845. Abcam, USA according to the manufacturer's instructions.

\section{Plasminogen activator inhibitor-1 (PAI-1)}

PAI-1 was measured using RK003A ZYMUTEST Rat ELISA PAI-1 Kit, Hyphen Biomed, France according to the manufacturer's instructions.

Tumor necrosis factor- $\alpha$ (TNF- $\alpha$ )

TNF- $\alpha$ was measured using Quantikine ELISA, Rat TNF- $\alpha$ kit, Catalog Number: RTA00 from USA \& Canada | R\&D Systems, Inc [19].

Interferon- $\gamma$ (IFN- $\gamma)$

IFN- $\gamma$ was measured using Rat Interferon- $\gamma$ ELISA Kit, Catalog Number: CSBE04579r, CUSABIO [19].

Interleukin-8 (IL-8)

IL-8 was measured using Rat IL-8 ELISA Kit, Catalog Number: ab7747, Abcam, USA [20].

Monocyte chemo attractant protein (MCP-1)

MCP-1 was measured using Rat MCP-1/CCL2 ELISA Kit, Catalog Number: RAB0058, Sigma Aldrich according to the manufacturer's instructions.

\section{Statistical Analysis}

Data were expressed as the mean \pm standard error (SE). Statistical analysis was performed using the statistical package for social science (SPSS, Chicago, IL) version 16 statistical software. Data were analyzed by one-way analysis of variance 
followed by Post-Hoc-least significant difference analysis; the level of significance was set at $p<0.001$.

\section{RESULTS}

Flow Cytometric Analysis of MSCs Surface Markers

MSCs showed positive expressions for surface markers CD90, CD29 and negative expression for CD34 by flow cytometric analysis (Figure. 1).

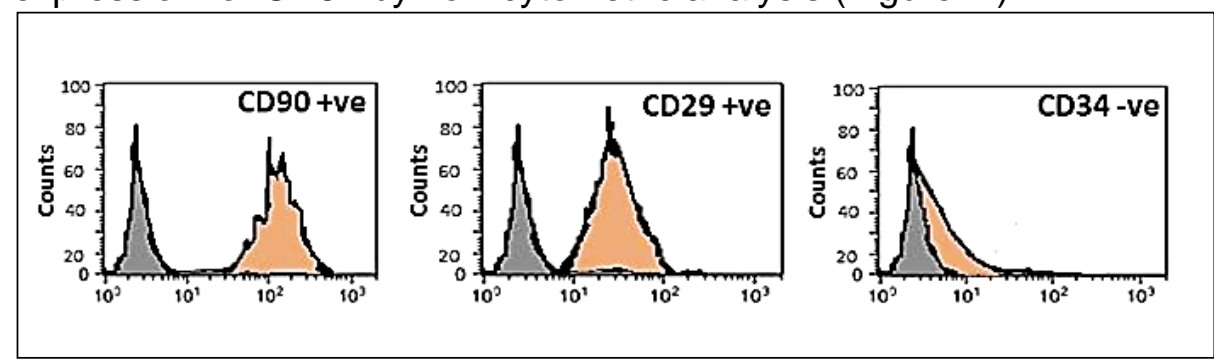

(a)

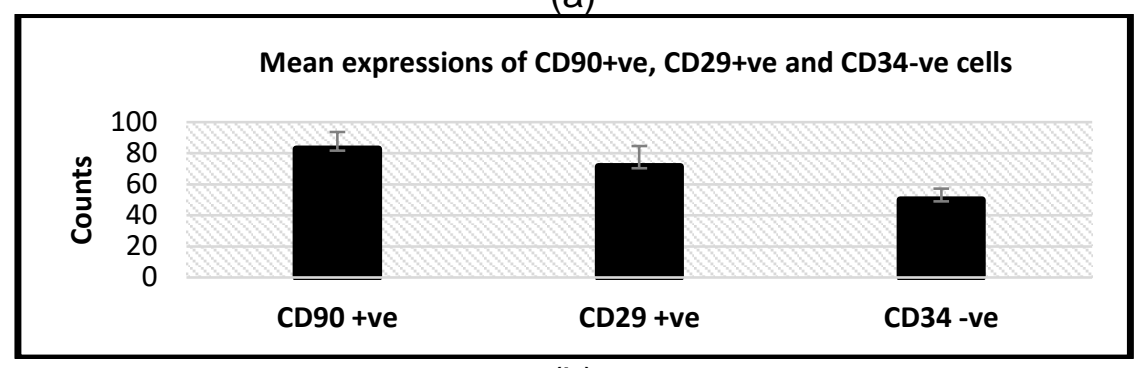

(b)

Figure 1. (a) Flow cytometric analyses for MSCs. Cells were positive for CD90 and CD29 but negative for CD34. (b) Mean expressions \pm Standard Deviations of CD90+ve, CD29+ve and CD34-ve cells of three independent experiments.

\section{Detection of MSCs in Lung:}

PKH26 labeled stem cells were detected in the lung tissue of rats by fluorescence microscope (Figure. 2).

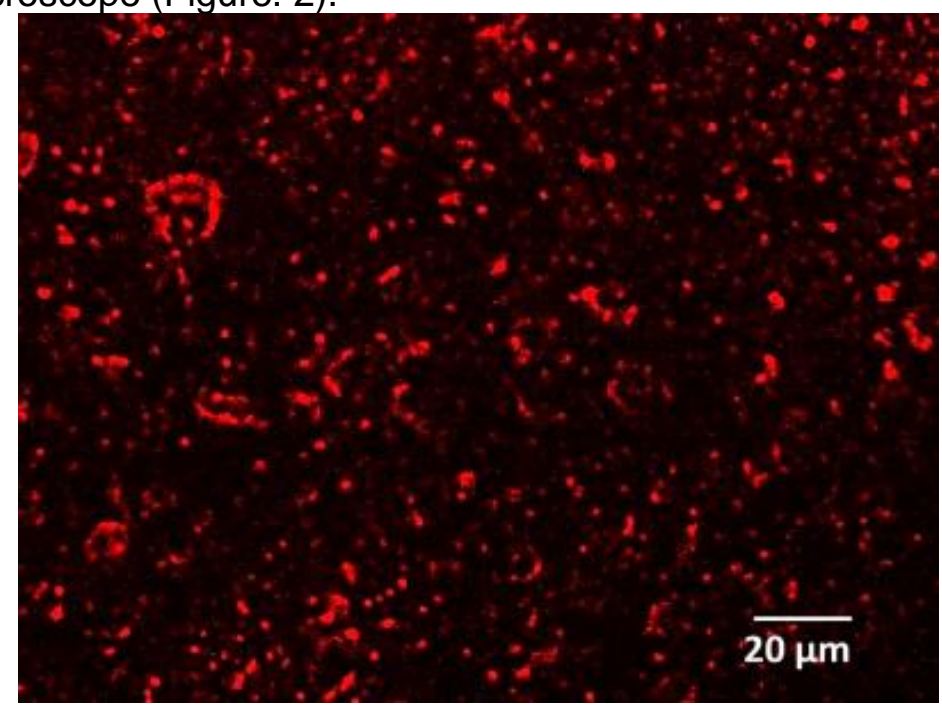

Figure 2. PKH26 labeled stem cells were detected in lung tissue of rat as a red fluorescence dye. 


\section{Coagulation Markers}

Table 1. The influence of MSCs on coagulation markers in MTX- induced lung injury rat model

$\begin{array}{cccc}\text { Parameters } & \begin{array}{c}\text { PAR-1 } \\ \text { relative exp. }\end{array} & \begin{array}{c}\text { Fibrinogen } \\ \mathbf{p g} / \mathbf{m g}\end{array} & \begin{array}{c}\text { PAl-1 } \\ \mathbf{n g} / \mathbf{m g}\end{array} \\ \text { Groups } & 0.38 \pm 0.06 & 17.16 \pm 1.08 & 2.62 \pm 0.24 \\ \text { Control } & 2.145^{\mathrm{a}} \pm 0.04 & 48.03^{\mathrm{a}} \pm 3.22 & 8.66^{\mathrm{a}} \pm 0.38 \\ \text { MTX } & 1.03^{\mathrm{b}} \pm 0.04 & 26.49^{\mathrm{b}} \pm 1.58 & 2.9^{\mathrm{b}} \pm 0.23 \\ \text { MTX/MSCs } & & \end{array}$

Data are expressed as mean \pm SE. MTX: Methotrexate group. MSCs: Mesenchymal stem cells group. a: Statistically significant as compared to control group, $p<0.001$. b: Statistically significant as compared to MTX group, $p<0.001$.

MTX caused statistical elevation $(p<0.001)$ in all coagulation markers as compared to those of control ones (Table 1). Relative expression of PAR-1 of control rats recorded mean values of $(0.38 \pm 0.06)$ which were increased under MTX injection to record $(2.145 \pm 0.04)$. The treatment with MSCs decreased the relative expression of PAR-1 significantly $(p<0.001)$ to record $(1.03 \pm 0.04)$. At the same time, the mean values of fibrinogen increased from $(17.16 \pm 1.08)$ of control animals to $(48.03 \pm 3.22)$ of MTX group. These results declined significantly $(p<0.001)$ to record (26.49 \pm 1.58$)$ in MTX/MSCs group. Likewise, the mean values of PAl-1 levels detected $(2.62 \pm 0.24)$ in control rats which increased to $(8.66 \pm 0.38)$ after MTX injection. MSCs treatment decreased those values to record $(2.9 \pm 0.23)$ (Table 1).

\section{Inflammatory Markers}

Table 2 elucidates that MTX injection caused a significant elevation $(p<0.001)$ in lung inflammatory markers compared to control rats. On the other hand, treatment with MSCs markedly decreased these markers compared to MTX group $(p<0.001)$. In more details, MTX increased TNF- $\alpha$, IFN- $y$, IL-8 and MCP-1 about 13.2, 5.4, 3.4 and 3.2 folds respectively when compared to controls. MSCs treatment significantly $(p<0.001)$ decreased the pre-mentioned inflammatory marker levels when compared to MTX group.

Table 2. The influence of MSCs on the inflammatory markers in MTX-induced lung injury rat model

\begin{tabular}{ccccc} 
Parameters & $\begin{array}{c}\text { TNF-a } \\
\text { Gg/mg }\end{array}$ & $\begin{array}{c}\text { IFN-Y } \\
\mathbf{~ p g} / \mathbf{m g}\end{array}$ & $\begin{array}{c}\text { IL-8 } \\
\mathbf{~ p g} / \mathbf{m g}\end{array}$ & $\begin{array}{c}\text { MCP-1 } \\
\text { pg/mg }\end{array}$ \\
\hline Control & $3.54 \pm 0.01$ & $21.18 \pm 0.94$ & $32.24 \pm 1.26$ & $63.1 \pm 0.83$ \\
MTX & $46.82^{\mathrm{a}} \pm 2.07$ & $115.46^{\mathrm{a}} \pm 1.57$ & $111.5^{\mathrm{a}} \pm 2.11$ & $204.8^{\mathrm{a}} \pm 14.2$ \\
MTX/MSCs & $22^{\mathrm{b}} \pm 1.32$ & $77.7^{\mathrm{b}} \pm 2.1$ & $57.29^{\mathrm{b}} \pm 1.42$ & $113.78^{\mathrm{b}} \pm 5.9$ \\
\hline
\end{tabular}

Data are expressed as mean \pm SE. MTX: Methotrexate group. MSCs: Mesenchymal stem cells group. a: Statistically significant as compared to control group, $p<0.001$. b: Statistically significant as compared to MTX group, $p<0.001$.

\section{Blood Platelets and Total Leukocyte Count}

Data illustrated in Table 3 showed that blood platelet count was increased significantly $(p<0.001)$ after MTX treatment with a percentage of $140.5 \%$ when compared to control rats. MSCs treatment decreased blood platelet count with a percentage of $34.3 \%$ compared to MTX group. Total leukocyte count increased markedly by MTX injection to record a percentage of change of $187.1 \%$ compared to 
controls. In MTX/MSCs group, a significant decrease $(p<0.001)$ in total leukocyte count was observed recording a percentage of decline of $58.2 \%$ compared to MTX group.

Table 3. The influence of MSCs on blood platelets and total leukocyte count in MTX-induced lung injury rat model

\begin{tabular}{ccc}
\hline Proups & $\begin{array}{c}\text { Platelets } \\
\text { X } \mathbf{1 0 0 0}\end{array}$ & $\begin{array}{c}\text { Total Leukocytes } \\
\mathbf{x} 1000\end{array}$ \\
\hline Control & $329.16 \pm 13.06$ & $6.46 \pm 0.84$ \\
MTX & $791.66^{\mathrm{a}} \pm 17.18$ & $18.55^{\mathrm{a}} \pm 0.66$ \\
MTX/MSCs & $520.0^{\mathrm{b}} \pm 18.52$ & $7.75^{\mathrm{b}} \pm 0.69$ \\
\hline
\end{tabular}

Data are expressed as mean \pm SE. MTX: Methotrexate group. MSCs: Mesenchymal stem cells group. a: Statistically significant as compared to control group, $p<0.001$. b: Statistically significant as compared to MTX group, $\mathrm{p}<0.001$.

\section{DISCUSSION}

The current work elucidated the therapeutic role of MSCs against clotting activity in MTX-induced lung injury rat model. In the coagulation cascade; the pro-thrombin was converted into thrombin. Thrombin then converted fibrinogen into insoluble fibrin, at the same time; thrombin activated platelets via triggering of thrombin receptor PAR-1 which was expressed on platelets. This resulted in the formation of a plateletfibrin thrombus [3]. On the other hand, fibrinolysis was enhanced via plasmin which was activated by plasminogen activators [21]. PAI-1 hindered plasminogen activators which in turn impaired fibrin breakdown. Consequently, this enhanced fibrin generation and deposition of clots in the microvasculature. So, PAI-1 correlated with the outcome and severity of lung dysfunction and scattered intravascular coagulation [22]. In this study, MTX produced a significant elevation in coagulation factors; PAR1 , fibrinogen as well as anti-fibrinolysis factor PAI-1 and platelet count which reflected thrombin-dependent PAR-1 signaling and platelets aggregation $[3,4]$. All at once, there was a parallel elevation in inflammatory factors TNF- $\alpha$, IFN- $\gamma$, IL-8 and MCP-1 combined with an elevation in total leukocyte count. This evidenced that coagulation and inflammation here were dual systems playing pivotal roles in host defense against MTX-induced lung injury. The elevation of inflammatory mediators in this study might be due to the increase in the stimulation of Toll-like receptor 2 on resident macrophages by MTX which in turn enhanced the emission of proinflammatory cytokines $[9,23]$. Thus, it was considered that increased inflammation can intensify coagulation that, in turn, boosted inflammation [24,25]. Moreover, TNF$\alpha$, IFN-y, IL-8, and MCP-1 influenced tissue factors which initiated coagulation cascade [26] and down-regulated anticoagulant thrombomodulin [3]. Additionally, TNF- $\alpha$ enhanced the endothelial cells to produce anti-fibrinolysis PAl-1 [23]. This study revealed elevation in MCP-1 and IL-8 which plays an important role in clotting activity $[27,28]$. MCP-1 was secreted by monocyte, macrophage, and dendritic cells and was anchored in endothelial membrane. Platelet derived growth factors were the main inducers of MCP-1 gene [29]. More to the point, the activated platelets stimulated NF-KB in endothelial cells and enhanced the expression of leukocyte receptors which induced the secretion of MCP-1 and IL-8 [23]. Besides, the significant increase in the levels of lung PAR-1 expressed on many different pulmonary cells, as fibroblasts, macrophages, epithelial and endothelial cells might represent another cause for elevated MCP-1 and IL-8 chemotaxis molecules [28]. Subsequently, the elevation in total leukocyte count in MTX-induced lung injury group was related to the increase of MCP-1 and IL-8 which induced chemotaxis of monocytes from the bone marrow into lung inflamed tissues [30]. Several studies 
demonstrated the immune-modulatory, anti-inflammatory and anti-coagulant effects of MSCs therapy in different models [31,32]. MSCs had the ability to migrate to injured sites and secrete numerous paracrine factors then regulate endothelial, epithelial permeability and decrease lung inflammation [33]. In the current study labeled MSCs were detected in lung tissues. MSCs produced downregulation in both coagulation as well as inflammatory markers in MTX-induced lung injured rats. According to Choi et al. [34]. TNF- $\alpha$ enhanced MSCs to secrete TNF- $\alpha$-stimulated gene 6 protein (TSG-6), which interrelated with CD44 receptor on resident macrophages suppressing Toll-like receptor 2 and in turn pro-inflammatory cytokine production. In addition, MSCs were able to switch macrophages from the proinflammatory macrophage $\mathrm{M} 1$ to suppressor $\mathrm{M} 2$ phenotype, and $\mathrm{T}$ helper-1 to $\mathrm{T}$ helper-2. This in turn suppressed TNF- $\alpha$, IFN- $\gamma$, IL- 8 and MCP-1 and upregulated the anti-inflammatory cytokines $[35,36]$. MSCs seemed to exert an its anti-inflammatory response by increasing the production of TGF- $\beta 1$ [8]. On the light of the upper facts, it could be elicited that MSCs hypo-coagulation function might take place mainly through downregulation of inflammatory mediators; TNF- $\alpha$, IFN- $\gamma$, IL-8 and MCP-1 induced by MTX [37].

\section{CONCLUSION}

It could be concluded that MSCs had therapeutic potency against clotting development which represented the main risk for lung thrombosis and fibrosis based on their anti-inflammatory and immune-modulatory functions. This study opens the outlook for MSCs as a new therapeutic agent that moderates coagulation and inflammation together in clinical studies.

Funding: This research received no external funding.

Acknowledgments: Authors acknowledge Prof. Dr. Sanaa Mohamed Rifaat Wahba, Prof. of Histology \& Histochemistry and department instructor of Scientific English - Zoology Department, Faculty of Women for Arts, Science and Education, Ain Shams University for her guidance and assistance in language editing.

Conflicts of Interest: The authors declare no conflict of interest.

\section{REFERENCES}

1. Wuyts WA, Agostini C, Antoniou KM, Bouros D, Chambers RC, Cottin V, Egan JJ, Lambrecht BN, Lories R, Parfrey $\mathrm{H}$, Prasse A, Robalo-Cordeiro C, Verbeken $\mathrm{E}$, Verschakelen JA, Wells AU, Verleden GM. The pathogenesis of pulmonary fibrosis: a moving target. Eur Respir J. 2013;41:1207-18.

2. Kalathottukaren MT, Kizhakkedathu JN. 2-Mechanisms of blood coagulation in response to biomaterials: Extrinsic factors A2 - Siedlecki, Christopher A. Hemocompatibility of Biomaterials for Clinical Applications. Woodhead Publishing; 2018. pp. 29-49.

3. Anna K. The interaction of inflammation and coagulation systems. SCIREA Journal of Biology. 2016;1:93-105 .

4. Lin C, Borensztajn K, Spek CA. Targeting coagulation factor receptors - proteaseactivated receptors in idiopathic pulmonary fibrosis. J Thromb Haemost. 2017;15:597607.

5. Jain A, Barrile R, van der Meer AD, Mammoto A, Mammoto T, De Ceunynck K, Aisiku O, Otieno MA, Louden CS, Hamilton GA, Flaumenhaft R, Ingber DE. Primary Human Lung Alveolus-on-a-chip Model of Intravascular Thrombosis for Assessment of Therapeutics. Clin Pharmacol Ther. 2018;103:332-40.

6. Dempsey OJ, Miller D. Idiopathic pulmonary fibrosis. BMJ. 2013;347:f6579.

7. Takano M, Nekomoto C, Kawami M, Yumoto R. Role of miR-34a in TGF- $\beta 1$ - and DrugInduced Epithelial-Mesenchymal Transition in Alveolar Type II Epithelial Cells. J Pharm Sci. 2017;106:2868-72. 
8. Mani A, Blackwell SC, Refuerzo JS. 689:Mesenchymal stem cells exert anti-inflammatory effects on lipopolysaccharide induced human uterine smooth muscle cells effects on lipopolysaccharide induced human uterine smooth muscle cells. Am J Obstet Gynecol. 2018;218:S414.

9. Fikry EM, Hassan WA, Gad AM. Bone marrow and adipose mesenchymal stem cells attenuate cardiac fibrosis induced by methotrexate in rats. $J$ Biochem Mol Toxicol. 2017;31:1-8.

10. Fikry EM, Safar MM, Hasan WA, Fawzy HM, El-Denshary ES. Bone Marrow and Adipose-Derived Mesenchymal Stem Cells Alleviate Methotrexate-Induced Pulmonary Fibrosis in Rat: Comparison with Dexamethasone. J Biochem Mol Toxic. 2015;29:321-9.

11. El-Hady EMF. A study on the effect of stem cells as compared with dexamethasone on chemotherapy-induced pulmonary fibrosis in rat. CU Theses. 2015;1-18.

12. Şen HS, Şen V, Bozkurt M, Türkçü G, Güzel A, Sezgi C, Abakay Ö, Ibrahim K. Carvacrol and pomegranate extract in treating methotrexate-induced lung oxidative injury in rats. Med Sci Monit. 2014;20:1983-90.

13. Abdel Aziz MT, Atta HM, Mahfouz S, Fouad HH, Roshdy NK, Ahmed HH, Rashed LA, Sabry D, Hassouna AA, Hasan NM. Therapeutic potential of bone marrow-derived mesenchymal stem cells on experimental liver fibrosis. Clin Biochem. 2007;40:893-9.

14. Haasters F, Prall WC, Anz D, Bourquin C, Pautke C, Endres S, Mutschler W, Docheva $\mathrm{D}$, Schieker M. Morphological and immunocytochemical characteristics indicate the yield of early progenitors and represent a quality control for human mesenchymal stem cell culturing. J Anat. 2009;214:759-67.

15. Morigi M, Introna M, Imberti B, Corna D, Abbate M, Rota C, Rottoli D, Benigni A, Perico N, Zoja C, Rambaldi A, Remuzzi A, Remuzzi G. Human bone marrow mesenchymal stem cells accelerate recovery of acute renal injury and prolong survival in mice. Stem Cells. 2008;26:2075-82.

16. Wahba SMR, Abd-Elhalem SS, Azab AA. Possible role of moringa oleifera leaves extract on myeloid derived suppressor cells in benzene-induced leukemia. Europ $\mathrm{J}$ of Biomed AND Pharm sci. 2018;5:36-46.

17. El Asmar MF, Atta HM, Mahfouz S, Fouad HH, Roshdy NK, Rashed LA, Sabry D, Hassouna AAT, Fatma M. Efficacy of mesenchymal stem cells in suppression of hepatocarcinorigenesis in rats: possible role of Wnt signaling. J Exp Clin Canc Res, 2011; 30:49.

18. Chien EK, Sweet L, Phillippe M, Marietti S, Kim TT, Wolff DA, Thomas L, Eric B. Protease-activated receptor isoform expression in pregnant and nonpregnant rat myometrial tissue. J Soc Gynecol Invest. 2003;10:460-8.

19. Abd-Elhalem SS, Haggag NZ, El-Shinnawy NA. Bone marrow mesenchymal stem cells suppress IL-9 in adjuvant-induced arthritis. Autoimmunity, 2018;51:25-34.

20. Lin Z, Zhang $Y, X i a ~ Y, X u X$, Jiao $X$, Jun S. Salmonella enteritidis Effector AvrA Stabilizes Intestinal Tight Junctions via the JNK Pathway. The $\mathrm{J}$ of Biol Chem. 2016;291:26837-49.

21. Mary MJ, Saravanan L, Deecaraman M, Vijayalakshmi M, Umashankar V, Jaigopal S. Polymorphism of the PAl-1gene (4G/5G) may be linked with Polycystic Ovary Syndrome and associated pregnancy disorders in South Indian Women. Bioinformation. 2017;13:149-53.

22. Iba $T$, Jecko $T$. Clinical significance of measuring plasminogen activator inhibitor-1 in sepsis. J Intensive Care. 2017;5:56.

23. Van Hinsbergh VWM. Endothelium-role in regulation of coagulation and inflammation. Semin Immunopathol. 2012;34:93-106.

24. Van den Boogaard FE, Hofstra JJ, Brands X, Levi MM, Roelofs JJ, Zaat SA, Van't Veer C, van der Poll TS, Nebulized MJ. Rcombinant Human Tissue Factor Pathway Inhibitor Attenuates Coagulation and Exerts Modest Anti-inflammatory Effects in Rat Models of Lung Injury. J Aerosol Med Pulm Drug Deliv. 2017;30:91-9. 
25. Paparella D, Rotunno C, Guida P, Travascia M, De Palo M, Paradiso A, Carrozzo A, Ruggero R. Minimally invasive heart valve surgery:influence on coagulation and inflammatory response. Interact Cardiov Th. 2017;25:225-32.

26. Van der Poll T, Evert D. Cytokines as regulators of coagulation. Madame Curie Bioscience Database. 2013.

27. Akbari F, Ghorbani A, Farzad F. The assessment of proinflammatory cytokines in the patients with the history of cerebral venous sinus thrombosis. Iran J Neur. 2016;15:75-9.

28. Demetz G, Ilka O. The interface between inflammation and coagulation in cardiovascular disease. Int j inflamm. 2011; 2012.

29. Craig MJ, Robert DL. CCL2 (Monocyte Chemoattractant Protein-1) in cancer bone metastases. Cancer Metast Rev. 2006;25:611-9.

30. d'Audigier C, Cochain C, Rossi E, Guérin CL, Bièche I, Blandinières A, Marsac B, Silvestre J, Gaussem P, David MS. Thrombin receptor PAR-1 activation on endothelial progenitor cells enhances chemotaxis-associated genes expression and leukocyte recruitment by a COX-2-dependent mechanism. Angiogenesis. 2015;18:347-59.

31. Wang B, Wu S, Wang T, Ma Z, Liu K. Bone Marrow-Derived Mesenchymal Stem CellsMediated Protection Against Organ Dysfunction in Disseminated Intravascular Coagulation Is Associated With Peripheral Immune Responses. J Cell Biochem. 2017;118:3184-92.

32. Zhang R, Liu Y, Yan K, Chen L, Chen X, Li P, Chen F, Xiao-Dan J. Anti-inflammatory and immunomodulatory mechanisms of mesenchymal stem cell transplantation in experimental traumatic brain injury. J Neuro Inflamm. 2013;10:871.

33. Li X, Yue S, Luo Z. Mesenchymal stem cells in idiopathic pulmonary fibrosis. Oncotarget. 2017;8:102600-16.

34. Choi H, Lee RH, Bazhanov N, Oh JY, Prockop DJ. Anti-inflammatory protein TSG-6 secreted by activated MSCs attenuates zymosan-induced mouse peritonitis by decreasing TLR2/NF-kappaB signaling in resident macrophages. Blood. 2011;118:330-8.

35. Cho D, Kim MR, Jeong $\mathrm{H}$, Jeong $\mathrm{HC}$, Jeong $\mathrm{MH}$, Yoon $\mathrm{SH}$, Kim $\mathrm{YS}$, Ahn $\mathrm{Y}$. Mesenchymal stem cells reciprocally regulate the M1/M2 balance in mouse bone marrow-derived macrophages. Exp Mol Med. 2014;46:e70.

36. Lathrop MJ, Brooks EM, Bonenfant NR, Sokocevic D, Borg ZD, Goodwin M, Loi R, Cruz F, Dunaway CW, Chad S. Mesenchymal stromal cells mediate Aspergillus hyphal extract-induced allergic airway inflammation by inhibition of the th17 signaling pathway. Stem CelL Transl Med. 2014;3:194-205.

37. Wang B, Wu S, Wang T, Liu K, Zhang G, Zhang X, Yu J, Liu C, Chang-Cun F. Pretreatment with bone marrow-derived mesenchymal stem cells inhibits systemic intravascular coagulation and attenuates organ dysfunction in lipopolysaccharideinduced disseminated intravascular coagulation rat model. Chinese Med J-Peking. 2012;125:1753-9.

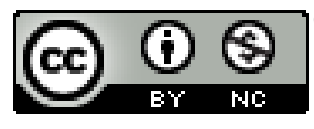

(c) 2018 by the authors. Submitted for possible open access publication under the terms and conditions of the Creative Commons Attribution (CC BY NC) license (https://creativecommons.org/licenses/by-nc/4.0/). 